\title{
A Remote Sensing Analysis of Adélie Penguin Rookeries
}

\section{Mathew R. Schwaller}

SAIC, Washington, DC

\section{Charles E. Olson Jr., Zhenqui Ma, and Zhiliang Zhu}

University of Michigan, Ann Arbor

Paul Dahmer

ERIM

The Adélie penguin (Pygoscelis adeliae) makes up the vast majority of bird biomass in the Antarctic. As a major consumer of krill, these birds play an important role in the Antarctic food web, and they have been proposed as an indicator species of the vitality of the Southern Ocean ecosystem. This study explores the terrestrial habitat of the Adélie penguin as a target for remote sensing reconnaissance. Laboratory and groundlevel reflectance measurements of Antarctic materials found in and around penguin rookeries were examined in detail. These analyses suggested data transformations which helped separate penguin rookeries from surrounding areas in Landsat Thematic Mapper imagery. The physical extent of penguin rookeries on Ross and Beaufort Islands, Antarctica, was estimated from the satellite data and compared to published estimates of penguin populations. The results suggest that TM imagery may be used to identify previously undiscovered

Address Correspondence to Dr. Mathew R. Schwaller, SAIC, 400 Virginia Ave., S.W., Washington, DC 20024

Received 25 August 1988; revised 16 February 1989. penguin rookeries, and the imagery may provide a means of developing new population estimation methods for Antarctic omithology.

\section{INTRODUCTION}

This paper describes satellite remote sensing methods used to estimate the size of Adélie penguin (Pygoscelis adeliae) nesting sites. Preliminary laboratory investigations studied the unique spectral characteristics of Adélie penguins and penguin guano (Schwaller et al., 1984). Furthermore, image analysis indicated that guano plus other debris from Adélie nesting sites created a unique organic soil that was distinguishable from surrounding areas by radiance recorded in satellite imagery (Schwaller et al., 1987). This study builds on previous work by examining laboratory reflectance measurements of Antarctic materials found in and around penguin rookeries, and by evaluating ground-level radiometric measurements. These analyses suggested data transformations which helped separate penguin rookeries from surrounding areas in Landsat Thematic Mapper (TM) im- 
agery. Finally, the physical extent of penguin colonies on Ross Island, Antarctica, was determined from satellite data and compared to published estimates of penguin populations.

The interest in Adélie penguins was motivated by the role these birds play in the Antarctic terrestrial and Southern Ocean ecosystems. Adélie penguins nest within rookeries on snow and ice-free beaches during the Austral summer, from late October to mid-February (Taylor, 1962). Rookeries vary in size from assemblages of a few nests to rookeries occupied by over 200,000 nests, equivalent to nearly 1 million adult birds and chicks (Wilson and Taylor, 1984; Croxall and Kirkwood, 1979).

The Southern Ocean ecosystem is unique because a single species of krill (Euphausia superba) is, either directly or indirectly, the main prey species of numerous species of whales, seals, squid, fish, and seabirds, including penguins. Because of the critical role played by krill, the Southern Ocean ecosystem may be vulnerable to human interference and to commercial exploitation of its living resources (El-Sayed, 1985). This is especially true since a krill fishery has recently begun in the Southern Ocean, with the prospect that modern methods could harvest immense quantities. Bird populations fluctuate with the availability of their prey species, and populations can drop precipitously when prey species are over-fished (Schaefer, 1970). Croxall and Prince (1979) suggested monitoring changes in the breeding numbers of krillfeeding seabirds, such as the Adélie penguin, may provide an index of the distribution and abundance of krill stocks. Such an index may be useful for managing catch limits, and it may also serve as an index of the vitality of the Southern Ocean ecosystem (SCAR, 1979).

Current baseline information on the distribution and continent-wide population of Adélie penguins is sketchy. International programs provide relatively accurate estimates of breeding populations in certain segments of Antarctica, most notably within areas of the Antarctic Peninsula and Ross Sea (Croxall and Kirkwood, 1979). Accurate estimates beyond these areas are unavailable, and recently quoted continent-wide estimates vary by up to an order of magnitude (Mougin and Prévost, 1980; Wilson and Taylor, 1984; Stonehouse, 1985).

A large fraction of the total Adélie population returns to established rookeries to breed during the Austral summer. Thus penguin rookeries make appealing targets for estimating populations. Al- though some birds will not return to any rookery in a given year, the breeding population found on rookeries and the true population should be highly correlated. Fluctuation in the actual population should be reflected on the rookery population in any given year. Furthermore, knowledge of the breeding population is often more important than an estimate of the total for assessing population dynamics.

Adélie penguin rookeries make appealing targets for remote sensing reconnaissance. A rookery's physical extent is well defined, and the penguins maintain a relatively constant packing density within the individual colonies that make up a rookery (Penney, 1968). The objective of the research reported here was to better understand the reflectance properties of penguin rookeries, and to propose methods by which these attributes may be exploited for penguin-counting techniques with satellite remote sensing.

\section{METHODS}

Laboratory spectrophotometric measurements were made of four ground cover categories collected at Cape Crozier on Ross Island, Antarctica: Adélie penguin guano, volcanic tuffs, basalt, and andesite. Nine spectra were measured of each of the four groups. Measurements were made with a Beckman DK-2A spectrophotometer, using barium sulfate as a reference standard. The spectrophotometer measures reflectance from a small sample (about $2 \mathrm{~cm}^{2}$ ), and records reflectance in the wavelengths from 0.4 to $2.7 \mu \mathrm{m}$. The reflectance data were subset and digitized into band reflectance values corresponding to the six TM reflectance channels by numerical integration. Thus, the final data set consisted of nine replicate measurements of four groups (guano, tuffs, basalt, and andesite) measured in six variables (TM Bands $1-5$ and 7; see Table 1 for TM band wavelengths).

Radiometric sampling was conducted in situ at Cape Crozier on Ross Island, Antarctica. Mea-

Table 1. TM Spectral Bands

\begin{tabular}{cc}
\hline Band & Wavelength $(\mu \mathrm{m})$ \\
\hline TM 1 & $0.45-0.52$ \\
TM 2 & $0.52-0.60$ \\
TM 3 & $0.63-0.69$ \\
TM 4 & $0.76-0.90$ \\
TM 5 & $1.55-1.75$ \\
TM 7 & $2.08-2.35$ \\
\hline
\end{tabular}


surements were made with a NASA three-band radiometer (Tucker et al., 1981) filtered to simulate TM Bands 3, 4, and 5. A halon panel was used as a reflectance standard. Four ground targets were chosen for radiometric measurements: areas within Adélie penguin rookeries (sample size, $n=40$, with sampling both within and between individual penguin colonies within the rookery), areas of rocky basalt $(n=16)$ and tuffs $(n=26)$, plus snow fields $(n=30)$. Measurements were made along transects between 0845 and 1045 local time on 1416 January 1986. (Data collection was timed to approximately match the Landsat- 5 daytime overpass, which occurs at about 0900 local time.) Due to constraints on time and logistics, radiometric measurements were not made of andesite exposures. After omitting outliers, the final ground-level reflectance data set consisted of the following sample sizes: rookery $(n=38)$, tuffs $(n=25)$, snow fields $(n=29)$, and basalt $(n=16)$, with three variables (reflectance in TM Bands 3, 4, and 5) measured in each group.

Analysis of Landsat TM data was conducted on a scene of the Ross Island area collected on 26 January 1985. Targets of interest (rookeries, snow fields, exposures of tuffs and basalt) were identified based on ground reconnaissance and map location, and pixel values from selected areas were chosen for analysis. To increase statistical independence among samples, $80 \%$ of the pixels were dropped from selected areas with a 1-in-5 systematic sampling. The tuffs data were not subsampled, however, because of the relatively small number of samples available over known tuffs exposures. Pixels were sampled from eight different classes of ground targets: the west Adélie penguin rookery at Cape Crozier (number of pixels sample for use in the statistical analysis, $n=90$ ); the east rookery at Cape Crozier $(n=21)$; the north rookery at Cape Bird $(n=22)$; snow fields and areas of sea ice ( $n=500)$; open ocean $(n=200)$; areas of basalt exposure $(n=132)$; and areas of tuffs exposure $(n=40)$. For the linear discriminant analysis described below, the three penguin rookeries were pooled into a single rookery class $(n=133)$.

Image analysis was conducted using the Land Analysis System at the NASA Goddard Space Flight Center Laboratory for Terrestrial Physics. Dark target subtraction was attempted as a means for atmospheric correction of the satellite imagery. However, a minimum digital value of 0 was found in each of the six reflective bands in the subscenes employed in the analyses described below. There- fore, no subtractions were conducted prior to image analysis.

A variation of the ratio technique helped reduce the topographic effect and to enhance the separation of penguin rookeries from other components in the Antarctic environment. The method involved data transformation from rectangular to spherical coordinates. The transformations for computing spherical coordinates are common knowledge (for example, Salas and Hille, 1974, pp. 381-382). Using these transformations, angular measures psi, phi, and theta were computed from TM Bands 3, 4, 5, and 7. These are ratiolike parameters, since they were computed from the TM data by dividing bands.

Linear discriminant analysis tested for statistically significant separation among ground targets. In the case of the laboratory measurements, where significant overlap between two groups of ground targets was observed in bivariate plots, pooled covariance matrices were used to estimate the discriminant function. Pooling the covariance matrices allowed estimation of the number of withingroup standard deviations separating group mean vectors-which defines the statistical separability of any two groups (Kendall, 1980). Separate within-group covariance matrices were used to estimate the discriminant functions for the radiometric and TM data (both raw and transformed), with the assumption of equal prior probabilities for the ground cover groups. Using Kendall's (1980) method, the accuracy of classifying ground targets based on the linear discriminant function was estimated after reapplication of the function to the same sample data that derived the discriminant function. Kendall's method increases the variance estimates to account for the problem of using the same data for training and testing the discriminant function.

All statistical analyses were conducted on SAS VMS Version 5 (SAS, 1985). Standard analyses were conducted using existing SAS functions; some of the analyses required custom programing with SAS MATRIX.

\section{RESULTS AND DISCUSSION}

Identification and classification of penguin rookeries in satellite imagery is based on the assumption that these targets possess relatively unique and consistent spectral qualities. Measurements were examined to determine whether such qualities were evident in the spectra of pure samples 


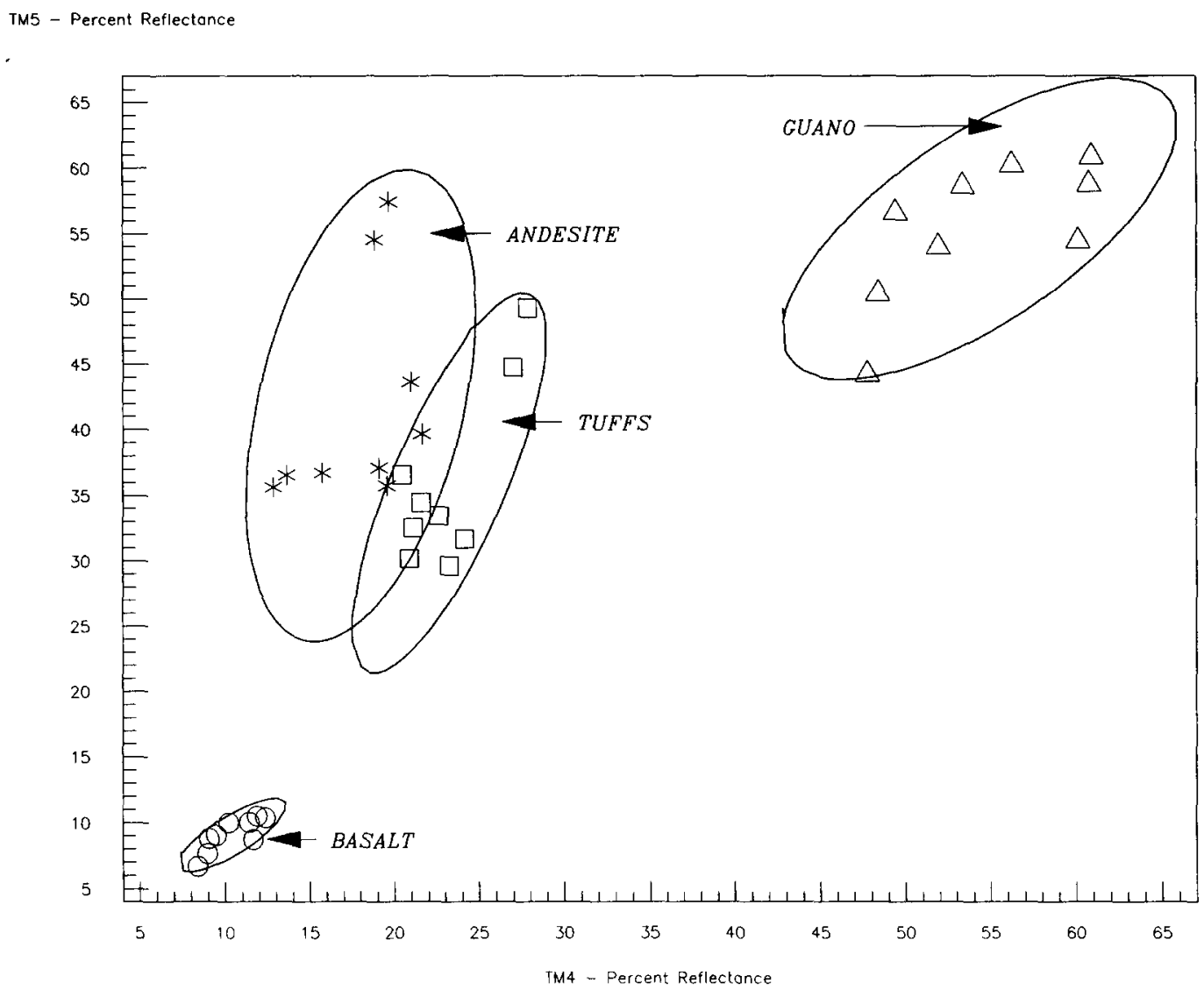

Figure 1. Bivariate plots ( $90 \%$ confidence region) of laboratory reflectance in TM Bands 4 and 5 common Antarctic materials, with actual sample reflectance points as indicated.

measured in the laboratory, and in radiometric measurements of well-defined field sites. These data were also used to suggest simple transformations to enhance the separability of penguin rookeries from other targets in TM imagery.

Laboratory reflectance data in TM Bands 3, 4, and 5 were plotted for visual analysis. These plots included illustration of the $90 \%$ confidence ellipsoids (Cooley and Lohnes, 1971, pp. 266-267) drawn around four groups of ground targets: guano, andesite, basalt, and tuffs (Fig. 1). Visual analysis of these graphs indicated relatively good separation of the groups, although there was some overlap, especially between andesite and tuffs. The bivariate plots were somewhat limited, however, because they are projections from three-dimensional to two-dimensional space. Groups can overlap significantly when projected into two dimensions and still be completely distinct in threedimensions. Linear discriminant analysis estimated the number of within-group standard deviations separating group mean vectors in the three-dimensional space of TM 3,4, and 5. The most nearly identical targets were andesite and tuffs, which were separated by 12.1 standard deviations. Assuming that the linear discriminant function was normal, the mean vectors were statistically separable at greater than the $99.99 \%$ level of confidence. All groups were perfectly separated when the discriminant function was applied to the sample data.

Visual analysis of in situ, hand-held radiometer data displayed in bivariate plots suggested that basalt, tuffs, and penguin colonies are readily separable by their reflectance in TM Bands 3,4 , and 5 (a subset of these plots is illustrated in Fig. 2). Generally, basalt is darkest in these three reflectance bands, tuffs has an intermediate reflectance, and the colony areas are the brightest of the three targets. Snow has a unique reflectance; it is highly reflective in TM Bands 3 (reflectance $>83 \%)$ and $4(>71 \%)$, but it is nearly black in TM Band $5(<5 \%)$. Visual examination of the bivariate plots also indicated a much greater variability in the in situ measurements, compared to the laboratory spectrophotometric data. This was especially true of the measurements collected 


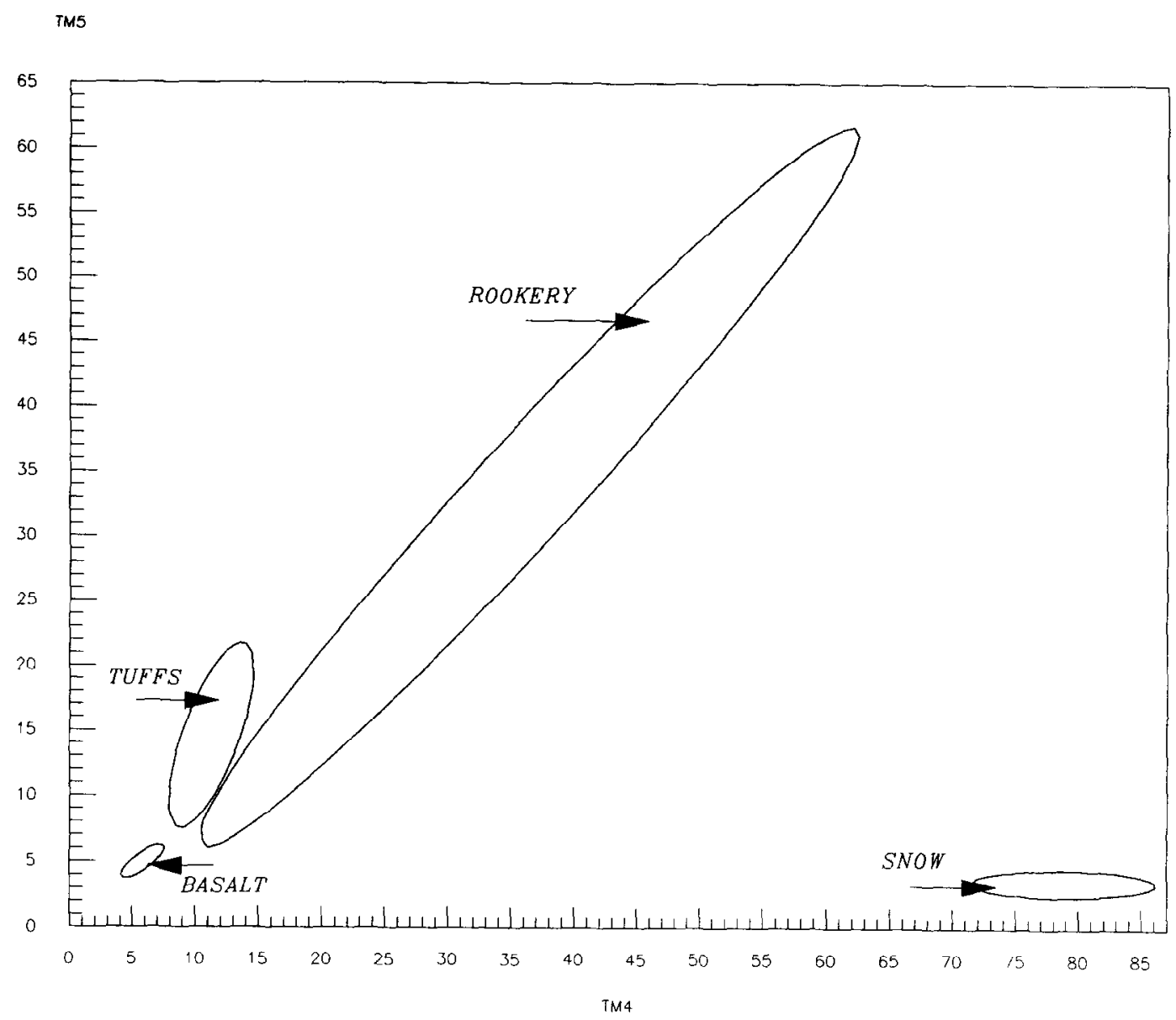

Figure 2. Bivariate plots ( $90 \%$ confidence region) of ground reflectance in TM Bands 4 and 5 for targets in and around the Adélie penguin rookeries on Cape Crozier.

within the penguin rookeries. The coefficient of variation for TM Band 5, for example, was 38.50 for radiometric data collected within the rookery, compared to 9.67 for laboratory spectrophotometric measurements of guano sampled within the same band. Linear discriminant analysis confirmed the visual analysis; as with the laboratory spectrophotometric data, all groups were perfectly separated when the discriminant function was applied to sample data.

Penguin rookeries were readily separated from other Antarctic materials based on laboratory and field reflectance measurements. One interpretation of Figs. 1 and 2 suggests that there are two elements which contribute to this separability: absolute target brightness (defined here are the radial distance from the origin to a data point) and target spectral features (angular distance from the axes to a data point). The radiance recorded in satellite inagery can be similarly interpreted. However, the absolute brightness recorded in satellite imagery is strongly influenced by the slope and aspect of ground targets. Assuming a clear atmosphere, slope and aspect of the terrain will have much less influence on the angular distance from the axes to a given datum. Inspection of Figs. 1 and 2 suggested that classification of TM imagery would benefit from a transformation which preserved the unique spectral features of Antarctic targets while minimizing the absolute brightness. The transformations used here converted rectangular coordinates of TM band reflectance into spherical coordinates.

Linear discriminant analysis gauged the separability of five ground targets (penguin rookeries, snow, ocean, basalt, and tuffs) based on measurements recorded in Bands 3, 4, 5, and 7 of Landsat TM imagery. Only one sample from the tuffs group was confused with the penguin rookery group when raw TM data were used in the analysis, and all other groups were perfectly separated. When the transformed data were evaluated, all groups 
(penguin rookery, snow, ocean, basalt, andesite, and tuffs) were perfectly separated by the discriminant function.

Discriminant analysis suggested that penguin rookeries are relatively easily identified in both the raw and transformed TM Data. Although data transformation does not provide any clear advantages in separating targets, the transformation appears to have some advantages when the qualitative aspects of image enhancement and interpretation are considered. First, the transformation lowered the coefficient of variation (c.v.) of the data in the TM bands examined. For the raw data, the c.v. for data collected over penguin rookeries in TM Bands $3,4,5$, and 7 were 20.5, 23.3, 26.7, and 25.4, respectively. For the transformed data, the c.v. for psi, phi, and theta were $1.70,6.03$, and 3.26 , respectively. These results suggested that, when displayed as a psi, phi, theta image, penguin rookeries will have a more uniform, homogeneous appearance than when displayed in any combination of TM Bands $3,4,5$, and 7 .

Analysis revealed that the transformation increased homogeneity of data collected over penguin colonies in other ways. An examination of Fig. 3 indicated that the average brightness recorded by the TM sensor of the north Cape Bird Adélie penguin rookery was lower than the Cape Crozier rookeries, and the TM band measurements collected over the west Cape Crozier rookery generally have a greater variability than those collected on Cape Crozier east. These differences can be attributed to slope and aspect of the terrains on which the rookeries are found. The aspect of the Cape Bird rookery pointed away from direct solar illumination at the time the imagery was collected, while the Cape Crozier rookeries pointed toward the sun. Thus the TM sensor recorded a generally lower band radiance over the Cape Bird rookery compared to the Cape Crozier rookeries, even

Figure 3. Bivariate plots ( $90 \%$ confidence region) of TM data in Bands 4 and 5 sampled from three penguin rookeries on Cape Crozier.

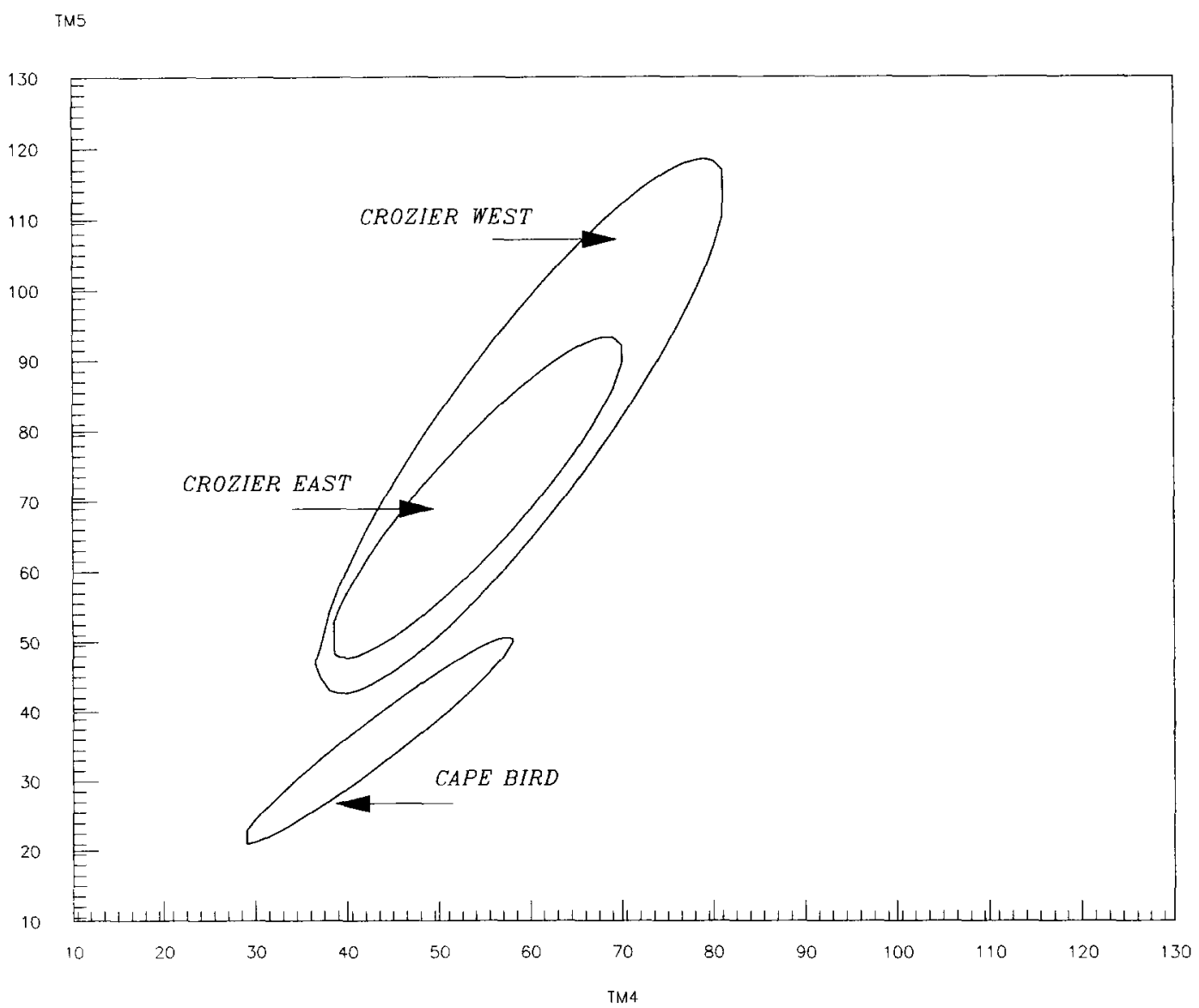




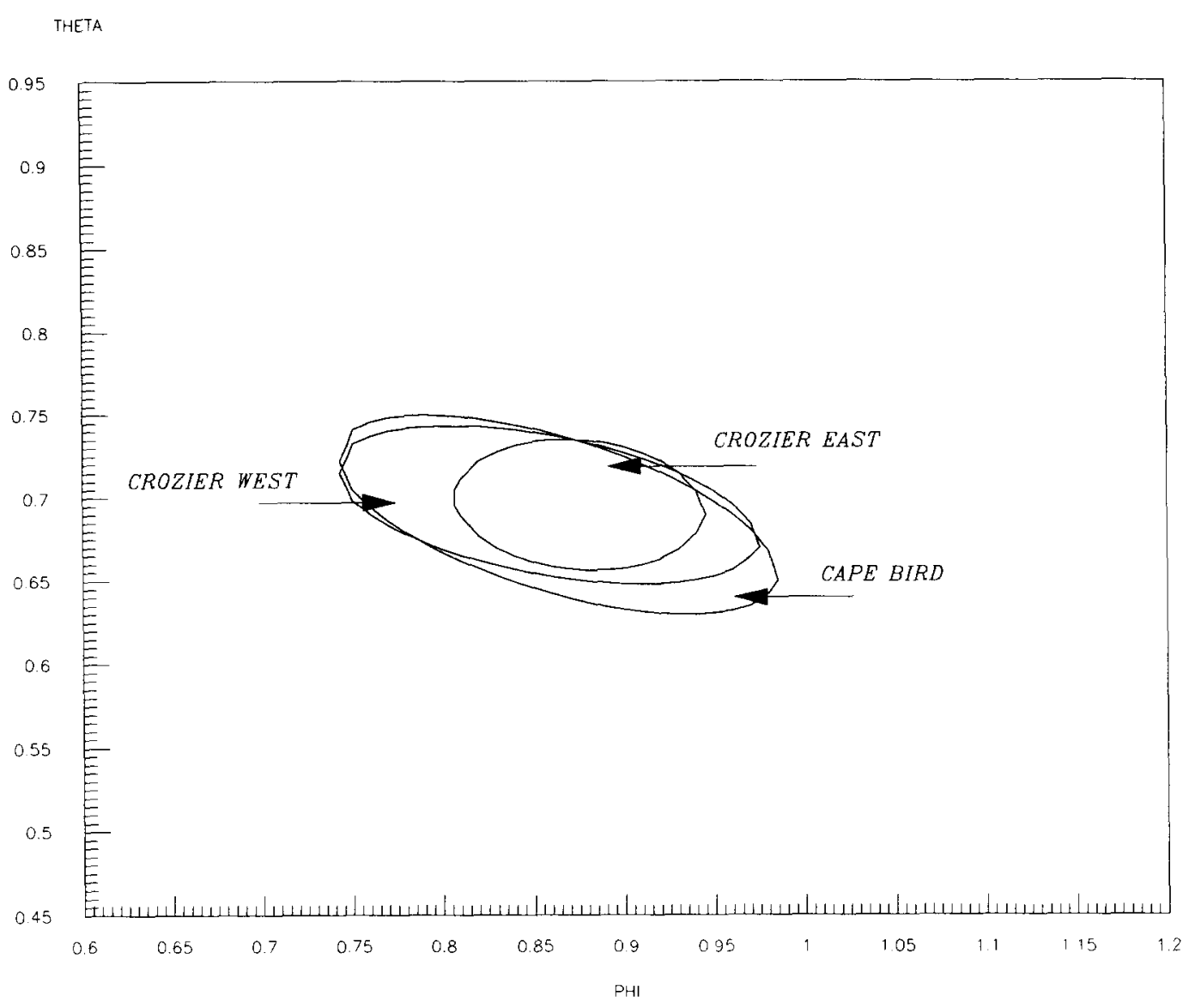

Figure 4. Bivariate plots ( $90 \%$ confidence region) of transformed TM data (theta and phi) sampled from three penguin rookeries on Cape Crozier.

though the rookery substrates are essentially identical. Even with similar aspects, the west rookery on Cape Crozier covers a much more topographically varied terrain than the Cape Crozier east rookery, which explains the greater variability in data recorded by the TM sensor over the west rookery. Visual analysis of graphs which plotted the transformed data indicated an increase in homogeneity when compared to raw data (a subset of transformed data plots is illustrated in Fig. 4). The centroids of the bivariate predictions for transformed TM data collected over the three rookeries were in close proximity, and the contours of the $90 \%$ confidence ellipsoids overlap much more closely than those of the raw data (Figs. 3 and 4).

TM Bands 3, 4, 5, and 7 were transformed to spherical coordinates, and the resulting three angular coordinates were displayed as images which were used to delineate the five Adélie penguin rookeries on Ross and Beaufort Islands. Once de-
Table 2. Estimates of Rookery Area

\begin{tabular}{lccc}
\hline \multicolumn{1}{c}{ Location } & $\begin{array}{c}\text { Number } \\
\text { of Pixels }\end{array}$ & $\begin{array}{c}\text { Population } \\
\text { (Breeding Pairs) }\end{array}$ & $\begin{array}{c}\text { Date of Pop. } \\
\text { Estimate }\end{array}$ \\
\hline Cape Crozier W. & 660 & 84,937 & 1966 \\
Cape Crozier E. & 126 & 12,970 & 1966 \\
Cape Bird N. & 131 & 23,600 & 1978 \\
Cape Bird S. & 55 & 10,000 & 1978 \\
Beaufort Is. & 66 & 21,000 & 1966 \\
\hline
\end{tabular}
(1984)

Source: Population estimates compiled by Wilson and Taylor

lineated, rookery areas were estimated by counting pixels (Table 2).

A positive correlation $\left(r^{2}=0.97\right)$ exists between population estimates compiled by Wilson and Taylor (1984) and rookery areas (Table 2). This correlation is indicative of a strong linear relationship, but should be regarded with caution. The relationship needs to be tested further: with a larger sample size, with current population data, and in areas where rookery populations are rapidly rising or falling. 
The lack of current population data for the five study sites is indicative of the current state of knowledge for all living resources in Antarctica. Regional surveys are sketchy, and continent-wide estimates of species populations rely primarily on guesswork-none are based on rigorous statistical survey design. If validated in more extensive tests, a linear relationship between rookery and population could serve as the basis for a continent-wide survey. Ratio estimates, for example, take advantage of the correlation between an auxiliary variable which is relatively easy to measure (such as rookery area from satellite imagery) and a variable of interest which is more difficult to measure (population). Typically, the efficiency and precision of the estimate is increased when an auxiliary variable is included in the estimate of a population total if the linear correlation between the two variables is greater than about +0.5 (Sheaffer et al., 1979).

Continent-wide estimates of penguin populations are currently hampered because large stretches of the Antarctic coastline remain unexplored. The regions for Marie Byrd Land to the Antarctic Peninsula, the Trinity Coastline of the Antarctic Peninsula, and the South Shetland Islands of the Scotia Sea have been suggested as locales where large undiscovered rookeries may lie (J. Croxall, personal communication). Based on reflectance properties, penguin rookeries were readily separated from other elements of the Antarctic landscape. These results, and the methods used to obtain them, hold promise for expanding the scope of Antarctic ornithology: for identifying previously undiscovered penguin rookeries and for developing continent-wide estimates of penguin populations.

This work was supported by the National Aeronautics and Space Administration Contract NAS 5-28755 and by National Science Foundation Grant DPP 85-07483. We would also like to acknowledge the contributions of Kathy Whenes, William Benninghoff, and David Parmellee.

\section{REFERENCES}

Cooley, W. W., and Lohnes, P. R. (1971), Multivariate Data Analysis, Wiley, New York.
Croxall, J. P., and Kirkwood, E. D. (1979), The Breeding Distribution of Penguins on the Antarctic Peninsula and Islands of the Scotia Sea, British Antarctic Survey, Cambridge.

Croxall, J. P., and Prince, P. A. (1979), Antarctic seabird and seal monitoring studies, Polar Record 19:573-595.

El-Sayed, S. Z. (1985), Phytoplankton of the Antarctic seas, in Key Environments-Antarctica (W. N. Bonner and D. W. H. Walton, Eds.) Pergamon, New York.

Kendall, M. G. (1980), Multivariate Analysis, 2nd ed., MacMillan, New York, 210 pp.

Mougin, J. L., and Prévost, J. (1980), Évolution annuelle des éffectifs et des biomasses des oiseaux antarctiques, Terre Vie Rév. Écol. 34:101-133.

Penney, R. L. (1968), Territorial and social behavior of the Adélie penguin, in Antarctic Bird Studies (O. L. Austin, Ed.), Antarctic Research Series Vol. 12, American Geophysical Union, Washington, DC.

Salas, S. L., and Hille, E. (1974), Calculus, Xerox, Lexington, MA.

SAS (1985), SAS User's Guide, SAS Institute, Cary, NC, 2 vols.

SCAR (1979), Fifteenth Meeting of SCAR. Charmonix, 16-26 May 1978. APPendix A. Working Group on Biology, Polar Rec. 19:304-312.

Schaefer, M. B. (1970), Men, birds and anchovies in the Peru current-dynamic interactions, Trans. Am. Fisheries Soc. 99:461-467.

Scheaffer, R. L., Mendenhall, W., and Ott, L. (1979), Elementary Survey Sampling, Duxbury Press, Boston, MA.

Schwaller, M. R., Benninghoff, W. S., and Olson, C. E., Jr. (1984), Prospects for satellite remote sensing of Adélie penguin rookeries, Int. J. Remote Sens. 5:849-853.

Schwaller, M. R., Olson, C. E., Jr., Benninghoff, W. S., and Whenes, K. M. (1987), Preliminary report on satellite remote sensing of Adélie penguin rookeries, Antarct. $J$. U.S. 21:205-206.

Stonehouse, B. (1985), Birds and mammals-penguins, in Key Environments-Antarctica (W. N. Bonner and D. W. H. Walton, Eds.), Pergamon, New York.

Taylor, R. H. (1962), The Adélie penguin (Pygoscelis adeliae) at Cape Royds, lbis 104:176-204.

Tucker, C. J., Jones, W. H., Kley, W. A., and Sundstrom, G. J. (1981), A three-band hand-held radiometer for field use, Science 211:281-283.

Wilson, G. J., and Taylor, R. H. (1984), Distribution and abundance of penguins in the Ross Sea sector of Antarctica, N.Z. Antarct. Rec. 6:1-7. 